\title{
Anthropo-Physiometric Features and Analysis of the Body Composition of Yakut Youth of Early and Late Puberty in the Republic of Sakha (Yakutia)
}

\author{
Lena I. Arzhakova, $\mathrm{PhD}^{1 *}$; Darima K. Garmaeva, $\mathrm{PhD}, \mathrm{ScD}^{1}$; Irina V. Kononova, $\mathrm{PhD}^{2}$; \\ Dmitry B. Nikitjuk, PhD, ScD ${ }^{3,5}$; Dmitry V. Nikolaev'; Ilona A. Markova ${ }^{1}$; \\ Maida U. Uarova ${ }^{1}$; Tatyana G. Degtyareva, $\mathrm{PhD}^{1}$; Tcyben K. Garmaev, $\mathrm{PhD}^{1}$ \\ ${ }^{I}$ M.K. Ammosov North-Eastern Federal University, Yakutsk, Russia \\ ${ }^{2} Y a k u t$ Science Centre of Complex Medical Problems, Yakutsk, Russia \\ ${ }^{3}$ Federal State Budgetary Institution of Science Federal Research Center for Nutrition, \\ Biotechnology and Food Safety, Moscow, Russia \\ ${ }^{4}$ Scientific Research Centre "MEDASS", Moscow, Russia \\ II.M. Sechenov First Moscow State Medical University, Moscow, Russia
}

\begin{abstract}
The aim of this study was to assess the anthropometric and physiometric indicators with an analysis of the body composition of young Yakuts of early and late puberty, living in the Republic of Sakha (Yakutia) (RS(Y)).

Materials and Methods: A total of 184 indigenous youths aged from 14 to 17 years, permanently residing in RS(Y), were examined. The study used generally accepted methods: anthropometry, dynamometry, spirometry, caliperometry, and body composition assessment by bioelectrical impedance analysis.

Results: Among Yakut youth living in RS(Y), an increase in musculoskeletal mass and a decrease in fat mass was observed in groups aged 14 to 17. In the period from 14 to 17 years, Yakut youth show significantly increased indicators of dynamometry, deadlift and vital lung capacity. The data above are accompanied by a decrease in the indicators of the content of fat mass and an increase in lean body mass, musculoskeletal mass and body cell mass. There is growth not only in skeletal muscles and skeleton, but also in the mass of internal organs. The data obtained will be used to develop an interval classification of body composition parameters for males of different ages in order to develop standards of physical development specifically for people living in RS(Y). (International Journal of Biomedicine. 2019;9(3):228-232.)
\end{abstract}

Key Words: puberty $\bullet$ anthropometry $\bullet$ dynamometry $\bullet$ spirometry $\bullet$ bioimpedance analysis

\section{Abbreviations}

BIA, bioelectrical impedance analysis; BCM, body cell mass; BFP, body fat percentage; BS, body size; BW, body weight; CC, chest circumference; $\mathbf{E C W}$, extracellular water; FM, fat mass; HC, hip circumference; ICW, intracellular water; LBM, lean body mass; MSM, musculoskeletal mass; PhA, phase angle; RMR, resting metabolic rate; VLC, vital lung capacity; WC, waist circumference.

\section{Introduction}

All over the world, modern living conditions lead to the trend of a steady deterioration in men's health indicators, a close relationship between a decrease in hormonal function and an increased frequency of metabolic syndrome and cardiovascular diseases, and a decrease in work capacity. The first urgent problem is the close relationship of a number of anthropometric and physiometric indicators as predictors of the manifestations of a group of diseases, such as metabolic syndrome, diabetes mellitus, and chronic non-infectious diseases with impaired sexual and reproductive functions. ${ }^{(1,2)}$ Anthropometric indicators 
of the body, reflecting its morphological and functional features, allow us to evaluate the nature of the most general patterns that underlie the development and improvement of man. In this understanding, the morphological characteristics of an individual can be considered as informational criteria for the characteristics of growth processes, and can serve as markers in the study of the impact on the body of climatic, sanitary, hygienic, social, and somatological factors, among others. ${ }^{(3)}$

Protecting the health of the younger generation is a primary task of the state since young people make up a significant part of the active working population. ${ }^{(4)}$ In this regard, the revision and development of regulatory regional indicators of anthropometric and physiometric factors, as well as methods for assessing body composition, are an urgent need. In addition, the presence of physical anthropology development standards allows in each case comparison of the physical status of the patient with those standards, which is fundamentally important when implementing a personalized approach, which is a trend in modern medicine. ${ }^{(5)}$

Body composition and features of anthropometric and physiometric indicators in young men in the Republic of Sakha (Yakutia) (RS(Y)) have been studied too little and not systematically, which was our main reason for choosing the topic of this study.

The aim of this study was to assess the anthropometric and physiometric indicators with an analysis of the body composition of young Yakuts of early and late puberty, living in $\mathrm{RS}(\mathrm{Y})$.

\section{Materials and Methods}

A total of 184 indigenous youths aged from 14 to 17 years, permanently residing in $\mathrm{RS}(\mathrm{Y})$, were examined. Examined young men were divided into two groups: early (Group A, n=89) and late (Group B, n=95) puberty.

The study used generally accepted methods. ${ }^{(6)}$ Anthropometric measurements included measurements of length $(\mathrm{cm})$ and weight $(\mathrm{kg})$ of the body, CC $(\mathrm{cm}), \mathrm{WC}(\mathrm{cm})$ and $\mathrm{HC}(\mathrm{cm})$. The study of functional indicators included measurement of VLC (1) and individual muscle strength. VLC was measured by spirometry using a SpiroS-100 apparatus.
Muscle strength was measured by the method of dynamometry using a hand dynamometer on both hands and a deadweight dynamometer. The thickness of the subcutaneous folds was determined by caliperometry. The content of the fat component was assessed based on BIA using the ABC-01 MEDASS device. ${ }^{(7)}$ The accuracy of impedance measurements was $2 \%$. Bioimpedancemetry was performed by the tetrapolar method using a sinusoidal current with a constant frequency of $50 \mathrm{kHz}$ with no more than $1 \mathrm{~mA}$ in the range of measured impedance values up to $1000 \mathrm{Ohm}$.

Statistical analysis was performed using Microsoft Office Excel 2010. Statistical methods used in processing the obtained material included calculating the distribution of individual attributes, assessing the main distribution patterns $(\mathrm{M} \pm \mathrm{SD})$, and evaluating the results on age centile scales. For data with normal distribution, inter-group comparisons were performed using Student's t-test. Differences of continuous variables departing from the normal distribution, even after transformation, were tested by the Mann-Whitney $U$-test. Group comparisons with respect to categorical variables are performed using chi-square tests. A probability value of $P<0.05$ was considered statistically significant.

The study was carried out in compliance with Ethical Principles for Medical Research Involving Human Subjects, Adopted by the 18th WMA General Assembly, Helsinki, Finland, June 1964, and amended by the 52nd WMA General Assembly, Edinburgh, Scotland, October 2000. All patients gave their written informed consent.

\section{Results and Discussion}

An important characteristic of the health of children and adolescents is the harmony of physical development since this is a very informative indicator that reflects the integral relationship between various anthropometric indicators (height and body weight), as well as the age and gender of the child. ${ }^{(8)}$ When assessing the results of measuring total body size according to age centile scales, it was found that most indicators are in corridor No. 4 (the area of average values. ${ }^{(6)}$ Figures 1 and 2 show the average anthropometric characteristics of Group A and Group B puberty.

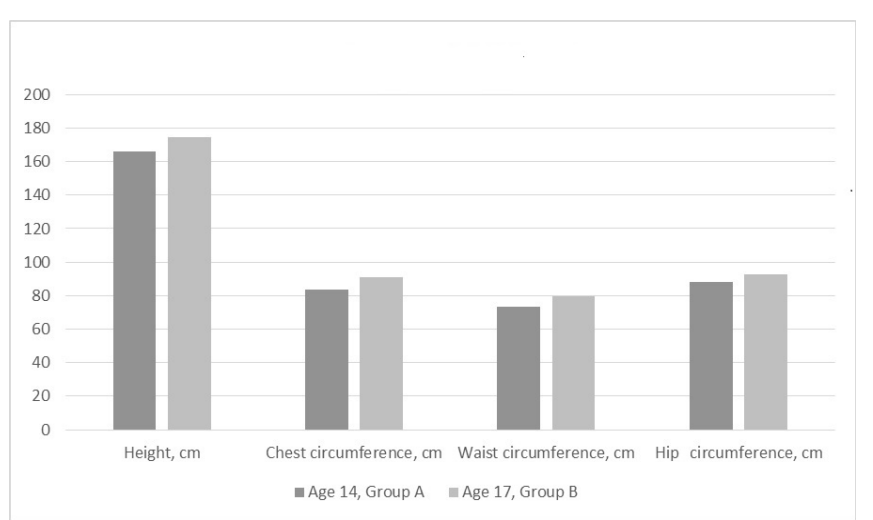

(1)

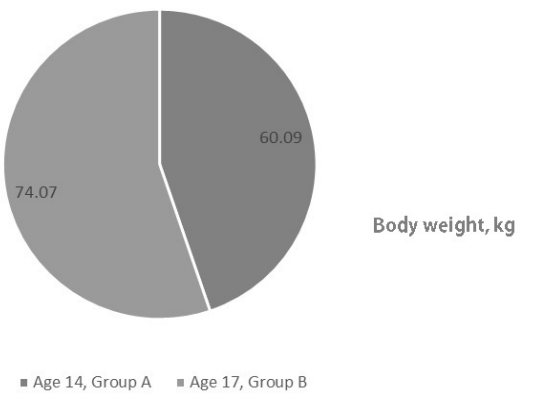

(2)

Figures (1) and (2). Average anthropometric characteristics. 


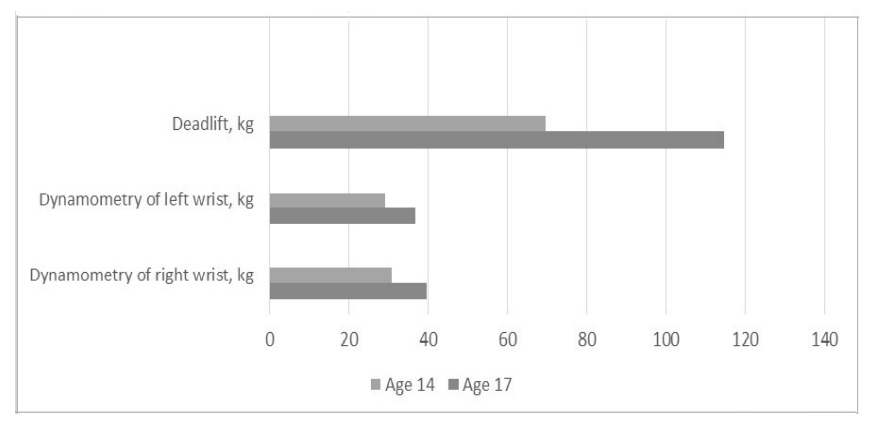

(3)

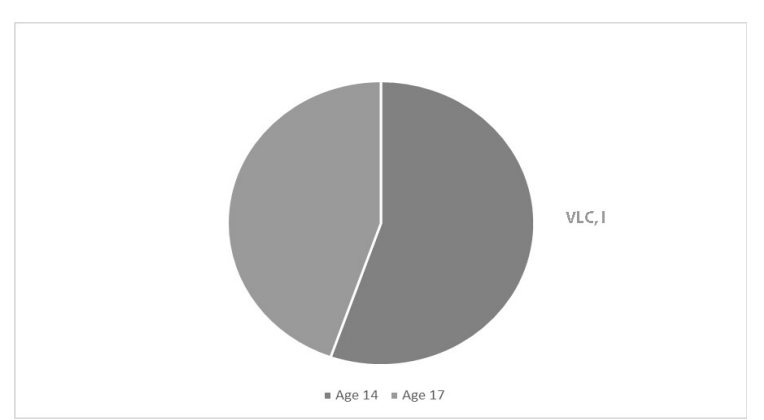

(4)

Figures (3) and (4). Physical indicators.

We found that Groups A and B had differences in all the presented parameters. Thus, the difference in body growth between Groups A and B was significant and amounted to $8.16 \mathrm{~cm}$, which corresponds to $4.91 \%$. BW varied by 19.98 $\mathrm{kg}$, which corresponds to $23.26 \%$. CC, WC and $\mathrm{HC}$ of the young men of Group B was greater than in Group A by $7.51 \mathrm{~cm}$ (9.11\%), $6.16 \mathrm{~cm}(8.39 \%)$ and $4.27 \mathrm{~cm}(4.78 \%)$, respectively. Thus, BW increases faster than body length growth, which is associated primarily with an increase in muscle mass. In addition, the horizontal dimensions of the body increase more than the vertical ones.

Physical development of adolescents. It was found that the indicators of deadlift and dynamometry of the left and right hand significantly increase in young men aged from 14 to 17 years by $64.68 \%, 25.97 \%$, and $23.89 \%$, respectively (Fig.3). Indicators of VLC also increase at an older age by $23.89 \%$ (Fig.4).

Caliperometry was used to measure the thickness of skin-fat folds in various parts of the body. It was shown that in young men of the examined groups, from 14 to 17 years, caliperometry indicators decreased. The changes in the shoulder area were especially pronounced: The caliperometry of the triceps decreased by $41.67 \%$, biceps - by $51.96 \%$, the lower part of the thigh - by $36.88 \%$. The changes measured in the region of the upper thigh, scapula, and iliac axis are insignificant, but in the region of the anterior abdominal wall the thickness of the skin-fat fold increased by $9.05 \%$ (Fig.5).

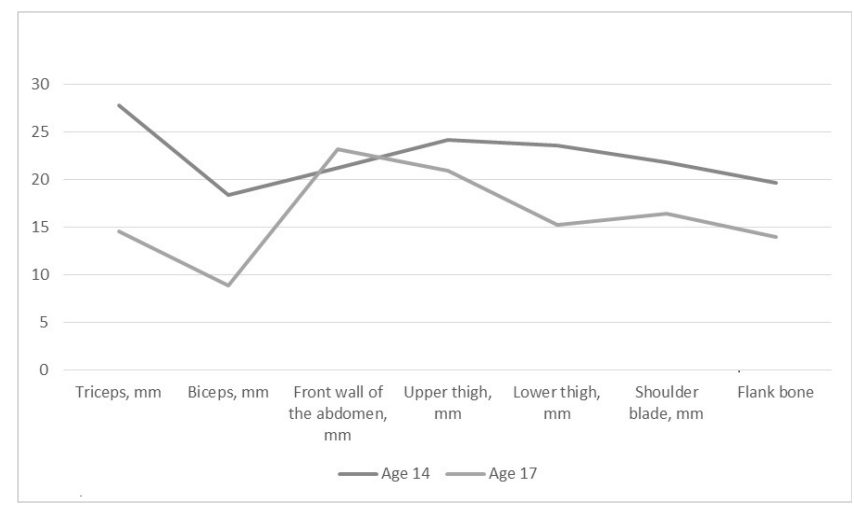

Fig.5. Caliperometry data.

The study of body composition by bioelectrical impedance analysis showed that in boys, the relative mass of adipose tissue in the period from 14 to 16 years increases by $5.5 \%$, lean mass by $14.9 \%$, and skeletal muscle mass by $13.9 \%$.

In young men of 17 years, the $\mathrm{PhA}$ values, according to the classification of O. Selberg( ${ }^{(9)}\left(6.6 \pm 0.6^{0}\right.$ is normal values), were determined as increased (Table 1). This suggests that those young men have high fitness. ${ }^{(7)}$ This is accompanied by a decrease in the indicators of the content of FM and an increase in LMM, MSM and BCM. There is growth not only in skeletal muscles and skeleton, but also in the mass of internal organs. RMR indicates the relative intensity of the metabolic processes; the compliance with age norms is observed.

The water content of both ECW and ICW was also normal. In clinical practice, most violations of the hydration state are associated with a change in the volume of extracellular fluid. The mineral mass content in young men 17-18 years old is maximum, which is an important indicator of bone tissue growth, which is a combination of organic substances, such as calcium, magnesium, and zinc. ${ }^{(10)}$

Thus, among Yakut youth living in $\mathrm{RS}(\mathrm{Y})$, a growth leap occurs between early and late puberty, accompanied by an increase in BW and BS. These features are accompanied by an increase in physical strength, expressed in readings of dynamometry and deadlift, as well as an increase in vital capacity of the lungs.

Measurements of the thickness of the skin-fat fold in the examined groups indicate that caliperometry decreases from 14 to 17 years; this is confirmed by BIA, where it was found that during the growth period the mass of skeletal muscle tissue increases faster than fat.

Thus, it can be argued that in young men, from early to late puberty, somatic growth is accompanied by a significant increase in musculoskeletal indicators and a decrease in fat mass. It should be noted that anthropometric indicators are consistent with changes in physiometric data; the scatter of data in the studied contingent of students is minimal. The age-related dependence of the rate of change in body length in children, noted in our study, is not always confirmed by similar studies conducted in different regions of the Russian Federation. Thus, according to the Health Centers, in boys the period of maximum growth rate and changes in body weight was observed somewhat earlier-at 14-15 years. ${ }^{(7)}$ For indigenous schoolchildren of the Republic of Tyva it was found that the length and BW of boys prevail over those of girls in all age periods, except for the age of puberty in girls. 
Table 1.

Bioelectrical impedance analysis (M $\pm S D$; min-max)

\begin{tabular}{|c|c|c|c|c|c|c|c|c|c|c|}
\hline Group & $\mathrm{PhA},{ }^{0}$ & $\begin{array}{c}\mathrm{FM}, \\
\mathrm{kg}\end{array}$ & $\begin{array}{l}\mathrm{LMM}, \\
\mathrm{kg}\end{array}$ & $\begin{array}{l}\text { BCM, } \\
\text { kg }\end{array}$ & $\begin{array}{l}\text { MSM, } \\
\text { kg }\end{array}$ & $\begin{array}{l}\mathrm{RMR}, \\
\mathrm{kcal} / \mathrm{m}^{2}\end{array}$ & Water, kg & $\begin{array}{c}\text { ECW, } \\
\text { kg }\end{array}$ & $\begin{array}{c}\text { ICW, } \\
\text { kg }\end{array}$ & $\begin{array}{l}\text { Mineral } \\
\text { mass, kg }\end{array}$ \\
\hline $\begin{array}{l}\text { Group A } \\
\text { Age 14-15 }\end{array}$ & $\begin{array}{l}6.80 \pm 0.63 \\
5.14-7.67\end{array}$ & $\begin{array}{c}13.37 \pm 10.1 \\
3.1-22\end{array}$ & $\begin{array}{c}52.21 \pm 6.01 \\
40.4-68\end{array}$ & $\begin{array}{c}30.01 \pm 4.20 \\
21.7-38.1\end{array}$ & $\begin{array}{c}30.04 \pm 2.16 \\
25-33.1\end{array}$ & $\begin{array}{c}879 \pm 48.53 \\
775-955\end{array}$ & $\begin{array}{c}38.22 \pm 4.97 \\
29.6-49.8\end{array}$ & $\begin{array}{c}15.97 \pm 1.81 \\
13-20.4\end{array}$ & $\begin{array}{c}22.24 \pm 3.19 \\
16.6-29.4\end{array}$ & $\begin{array}{l}2.94 \pm 0.32 \\
2.415-3.74\end{array}$ \\
\hline $\begin{array}{l}\text { Group B } \\
\text { Age 17-18 }\end{array}$ & $\begin{array}{l}7.40 \pm 1.73 \\
5.45-8.68\end{array}$ & $\begin{array}{c}7.75 \pm 4.71 \\
3.2-12.1\end{array}$ & $\begin{array}{c}53.55 \pm 9.40 \\
37.8-69.8\end{array}$ & $\begin{array}{c}31.72 \pm 7.57 \\
24.8-44.4\end{array}$ & $\begin{array}{c}37.31 \pm 15.76 \\
24.4-51.7\end{array}$ & $\begin{array}{c}917 \pm 161.49 \\
426-1121\end{array}$ & $\begin{array}{c}39.19 \pm 6.89 \\
25.7-51.1\end{array}$ & $\begin{array}{c}23.70 \pm 19.26 \\
11.9-44.5\end{array}$ & $\begin{array}{c}22.65 \pm 8.37 \\
15.6-39.7\end{array}$ & $\begin{array}{l}4.39 \pm 0.77 \\
3.882-5.63\end{array}$ \\
\hline
\end{tabular}

A puberty growth spurt in boys is observed at 14-15 years of age, and then the growth rate slows down. ${ }^{(11)}$ Studies by Uchakina showed that in the examined students living in the Amur region, the rates of physical development in indigenous children are slower than in the newcomer. In indigenous boys, the processes of increasing body length and mass begin earlier, proceed less intensively, with maximum activity in the initial period of the puberty, and stop by the end of hormonal adjustment; there is a sharp decrease in the rate of linear growth after 16 years, which indicates a slowdown of acceleration processes within the male population in the region. ${ }^{(12,13)}$ The physical development of adolescents living in central Russia is characterized by an increase in the proportion of children with harmonious physical development, an increase in the proportion of girls with a deficit of $\mathrm{BW}$, and an increase in the percentage of boys with excess BW. ${ }^{(14)}$ An increase in the proportion of modern schoolchildren with high and very high, as well as low and very low, values of body length and weight was noted. In other studies, it was found that the values of the anthropometric and physiometric characteristics of young men aged 17-20 years depend on the type of physique, the high growth of the examined individuals is accompanied by low values of life and strength indices. ${ }^{(15)}$ All the examined young men of 17-20 years old showed an increase in length and body weight, chest volume, and physiometric characteristics (VLC and muscle strength of both hands). ${ }^{(13)}$ According to BIA data at the Health Centers, in children there is an intensive increase in the absolute values of $\mathrm{LBM}, \mathrm{BCM}$ and MSM in boys, and BFP in girls, which is especially noticeable during puberty.(7) The results of NHANES III showed that from 12 to 18 years, ${ }^{(1)}$ American adolescents have increased rates of physical development, LBM and BMI as compared to a nationwide sampling. In studies of the Health Centers, when compared with the international sample of IOTF, the child population has "shifted" towards overweight. Thus, the average standardized BMI value for all ages for the all-Russian sample of children examined in the Health Centers, relative to the reference sample of IOTF, was +0.41 (SD) for boys, and the median percentage of BMI was significantly higher than in the comparison groups (with the exception of South Korean children).

\section{In conclusion:}

1. Among Yakut youth living in $\mathrm{RS}(\mathrm{Y})$, an increase in musculoskeletal mass and a decrease in fat mass was observed in groups aged 14 to 17 .

2. In the period from 14 to 17 years, Yakut youth show significantly increased indicators of dynamometry, deadlift and vital lung capacity.
3. The data above are accompanied by a decrease in the indicators of the content of fat mass and an increase in lean body mass, musculoskeletal mass and body cell mass. There is growth not only in skeletal muscles and skeleton, but also in the mass of internal organs.

The data obtained will be used to develop an interval classification of body composition parameters for males of different ages in order to develop standards of physical development specifically for people living in $\mathrm{RS}(\mathrm{Y})$. We hope that in the future, this will form the basis of in-depth monitoring of the effectiveness of prevention programs and the further improvement of managerial decisions aimed at reducing the incidence of certain diseases and improving the quality of life of the population.

This study is part of a comprehensive work related to the study of the individual typological characteristics of young men of indigenous and non-indigenous nationality as predictors of reproductive dysfunction of the male population in $\mathrm{RS}(\mathrm{Y})$.

\section{Competing Interests}

The authors declare that they have no competing interests.

\section{References}

1. Chaplygina EV, Aksenova OA, Vartanova OT, NorArevyan KA, Evtushenko AV. [Modern concepts about the human's constitution and its implications for medicine]. Modern problems of science and education. 2014:5. [Article in Russian].

2. Tikhonov DA, Mirin AA, Khayrullin RM. [Interrelation of genitometric and somatometric indicators of youths and young men as conjugate predictors for reproductive function]. Proceedings of the 9th Congress "Men's Health". St. Petersburg, RS "Men's Health"; 2013:312-314. [Article in Russian].

3. Kolokoltsev MM. [Anthropometric and physiometric characteristics of 17-20-year-old males with different development types]. Modern Problems of Science and Education. 2017:6:53. [Article in Russian].

4. On the all-Russian system for monitoring the state of physical health of the population, physical development of children, adolescents and youth. Resolution of the Government

*Corresponding author: Lena I Arzhakova, PhD. M.K. Ammosov North-Eastern Federal University, Yakutsk, the Republic of Sakha (Yakutia), the Russian Federation.E-mail: lenaarzhakova@, $\underline{\text { mail.ru }}$ 
of the Russian Federation dated December 29, 2001 N 916. [In Russian].

5. Tutelyan VA, Nikityuk DB, Klochkova SV, Alekseeva NT, Rassulova MA, Pogonchenkova IV, et.al. Using the integrated method anthropometry in sports and clinical practice. M.: "Sport"; 2017. [In Russian].

6. Belikova RM, Gainanova NK, Pyatunina OI. Methodology and evaluation of the results of anthropometric studie. Biysk: The Shukshin Altai State Humanities Pedagogical University; 2008: 11-16, 26-35. [In Russian].

7. Rudnev SG, Soboleva, NP, Sterlikov SA, Nikolaev DV, Starunova OA, Chernykh SP, et al. Bioimpedance study of body composition in the Russian population. M.: RIO TSNIIOIZ, 2014. [In Russian].

8. Baranov AA, Kuchma VR, Skoblina NA. The physical development of children and adolescents at the turn of the millennium. M.: Child Health Research Center of RAS; 2016. [In Russian].

9. Selberg O, Selberg D. Norms and correlates of bioimpedance phase angle in healthy human subjects, hospitalized patients, and patients with liver cirrhosis. Eur J Appl Physiol. 2002;86(6):509-16

10. Khrushcheva UV, Zubenko AD, Chedia ES. Verification and description of age-related variability of bioimpedance assessments of body metabolism. Proceedings of the scientific-practical conference "Diagnosis and treatment of the cardiovascular system disorders". Moscow; 2009: 353-7. [In Russian].
11. Omzar OS, Gritsinskaya VL. Comparative characteristics of somatometric indicators of schoolchildren of the indigenous population of Asia: Issues of preserving and developing the health of the population of the North and Siberia. Proceedings of the scientific and practical conference. Krasnoyarsk, 2010:58-59. [In Russian].

12. Degtyareva TG, Guryeva AB. [Some aspects of anatomical and anthropological studies of the male population of the Republic of Sakha (Yakutia)]. Modern Problems of Science and Education. 2015:3:118. [Article in Russian].

13. Uchakina RV, Filippova VV, Solovyova MI, Kozlov VK. [Physical and sexual development of girls living in various ecological zones of the Amur Region and Yakutia]. Bulletin of Physiology and Pathology of Respiration. 2004: 19: 42-46. [Article in Russian].

14. Miller VA, Kozakevich NV, Kozlovsky AA. [A centile method for assessing the harmony of the physical development of schoolchildren in Gomel]. Problems of Health and Ecology. 2012:3(33):17-22. [Article in Russian].

15. Lopatina OV. Trends in the physical and sexual development of older schoolchildren living in a large industrial city. Proceedings of the First All-Russian Scientific-Practical Conference. Chelyabinsk; 2000:55-56. [Abstract in Russian]. 16. Chumlea WC, Guo SS, Kuczmarski RJ, Flegal KM, Johnson CL, Heymsfield SB, et al. Body composition estimates from NHANES III bioelectrical impedance data. Int J Obes Relat Metab Disord. 2002;26(12):1596-609. 